\title{
¿A VIRTUOUS CIRCLE? THE EFFECTS OF UNIVERSITY-INDUSTRY RELATIONSHIPS IN A REGION WITH LOW ABSORPTIVE CAPACITY
}

Vega Jurado Jaider, Manjarrés Henríquez Liney, Fernández De Lucio Ignacio, Naranjo Africano Gloria.

\begin{abstract}
This article examines the effects of university-industry relationships (UIRs) in a Spanish region - Valencian Community - with low absorptive capacity. The analysis considers two effects of UIRs, one on business innovation and the other on the scientific production of academic researchers. The results reveal that UIRs have no significant effects on either firms' technological innovation or academic scientific production. Therefore, these results suggest that, in territories with low absorptive capacity, UIRs, mainly R\&D-based, do not produce the effects found in other contexts, which requires some rethinking about these types of territories.
\end{abstract}

\section{KEYWORDS}

absorptive capacity, innovation, scientific production, university-industry relationships 